\title{
PRODUTIVIDADE DE GRÃOS VERDES DO FEIJÃO-CAUPI SOB DIFERENTES REGIMES HÍDRICOS
}

\author{
HERBERT M. M. RAMOS ${ }^{1}$, EDSON A. BASTOS ${ }^{2}$, MILTON J. CARDOSO ${ }^{3}$, VALDENIR Q. \\ RIBEIRO $^{4}$, FÁBIO N. DO NASCIMENTO ${ }^{5}$
}

RESUMO: O objetivo deste trabalho foi avaliar a produtividade de grãos verdes, os componentes de produção e a eficiência do uso da água do feijão-caupi, sob regimes hídricos. O experimento foi conduzido na Embrapa Meio-Norte, em Teresina - PI, entre setembro e novembro de 2009. Foram avaliadas cinco lâminas de irrigação, estabelecidas com base em frações da evapotranspiração de referência (25; 50; 75; 100 e $125 \%$ da ETo), e as cultivares BRS Guariba e BRS Paraguaçu de feijão-caupi. Aplicou-se a irrigação por sistema de aspersão convencional fixo. Utilizou-se o delineamento experimental de blocos ao acaso, com quatro repetições e parcelas subdivididas (cultivares). As máximas produtividades de grãos verdes, $2.937,3 \mathrm{~kg} \mathrm{ha}{ }^{-1}$ (BRS Guariba) e 2.492,9 $\mathrm{kg} \mathrm{ha}^{-1}$ (BRS Paraguaçu), foram estimadas com as lâminas de irrigação de $354 \mathrm{~mm}$ e $423 \mathrm{~mm}$, respectivamente. A máxima eficiência de uso da água para a produtividade de grãos verdes foi observada com as lâminas de 275 mm e $231 \mathrm{~mm}$, para as cultivares BRS Paraguaçu e BRS Guariba, respectivamente. A cultivar BRS Guariba demonstrou melhor desempenho produtivo quando comparada com a cultivar BRS Paraguaçu.

PALAVRAS-CHAVE: Vigna unguiculata, feijão-verde, lâminas de irrigação.

\section{GREEN GRAIN YIELD OF COWPEA-BEAN UNDER DIFFERENT WATER REGIMES}

ABSTRACT: The objective of this study was to evaluate green grain yield, production components and water use efficiency for cowpea-bean under different water regimes. The experiment was carried out at Embrapa Meio-Norte, in Teresina, PI, Brazil, from September to November 2009. Five irrigation blades, based on reference evapotranspiration fractions (25, 50, 75, 100, and 125\% of ETo), and the evaluated cowpea-ben cultivars were BRS Guariba and BRS Paraguaçu. Irrigation was performed by conventional fixed sprinkling system. The experimental design was a randomized complete block with four replicates, in a split-plot arrangement (cultivars). Maximum green grain yields achieved 2,937.3 $\mathrm{kg} \mathrm{ha}^{-1}$ for BRS Guariba and 2,492.9 $\mathrm{kg}$ $\mathrm{ha}^{-1}$ for BRS Paraguaçu; these productivities were obtained under $354 \mathrm{~mm}$ and $423 \mathrm{~mm}$ irrigation blade, respectively. The irrigation blades of $275 \mathrm{~mm}$ and $231 \mathrm{~mm}$ for BRS Guariba and BRS Paraguaçu cultivars, respectively, accomplished the most efficiency in water use for green grain yield. BRS Guariba shows a better performance compared with BRS Paraguaçu.

KEY WORDS: Vigna unguiculata, green bean, water blades.

\section{INTRODUÇÃO}

A produção e o consumo de grãos verdes representam um mercado altamente promissor para o feijão-caupi, tornando-se boa opção de renda para os agricultores familiares (ROCHA et al., 2007). Por essa razão, tornou-se uma importante fonte de emprego e renda regional. A produção de

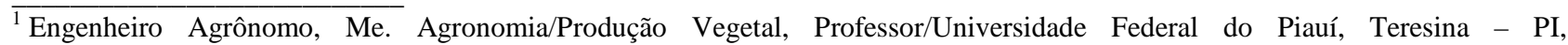
moreiraramos@uol.com.br

${ }^{2}$ Engenheiro Agrônomo, D.Sc. Irrigação e Drenagem, Pesquisador, Embrapa Meio-Norte, Teresina - PI, edson.bastos@embrapa.br

3 Engenheiro Agrônomo, D.Sc. em Fitotecnia, Pesquisador, Embrapa Meio-Norte, Teresina - PI, milton.cardoso@embrapa.br

4 Engenheiro Agrônomo, M.Sc. em Estatística Experimental, Pesquisador, Embrapa Meio-Norte, Teresina - PI, valdenir.queiroz@embrapa.br

5 Engenheiro agrônomo, mestrando do Programa de Pós-graduação em Agronomia/Universidade Federal do Piauí, Teresina- PI, nunesf.nascimento@gmail.com
}

Recebido pelo Conselho Editorial em: 22-10-2012

Aprovado pelo Conselho Editorial em: 16-2-2014 
grãos verdes tem um grande potencial para a expansão do consumo, como também para processamento industrial, especialmente, quando produzido na entressafra, ocasião em que o produto alcança elevados preços no mercado (FREIRE FILHO et al., 2007).

Atualmente, pesquisas realizadas por instituições públicas, como a Embrapa, têm permitido o lançamento de cultivares de feijão-caupi, as quais apresentam, além de resistência às doenças, caracteres agronômicos altamente favoráveis à produção de grãos secos e verdes (ROCHA et al; 2007; FREIRE FILHO et al. 2009; MATOS FILHO et al. 2009; MACHADO et al. 2008; ANDRADE et al. 2010; BENVINDO et al. 2010; BARROS et al. 2011). As cultivares, normalmente, apresentam elevada resposta à irrigação e podem ser utilizadas para a produção de grãos secos ou verdes.

A cultura do feijão-caupi responde à aplicação de água de forma diferente, em termos de produtividade de grãos e de componentes de produção, a depender das cultivares utilizadas e das condições climáticas da região explorada, o que tem sido demonstrado pelos resultados de diversos trabalhos executados em ecossistemas distintos. Porém, existe uma grande carência de informações sobre os efeitos da aplicação de lâminas de irrigação sobre a produtividade de grãos verdes e componentes de produção de grãos verdes do feijão-caupi.

De acordo com BRITO et al. (2012), de a agricultura irrigada consumir atualmente a maior parte da água doce disponível dos países em desenvolvimento, estimada entre 60 e $80 \%$ (CHRISTOFIDIS, 2008), encontrar meios de produzir mais alimentos com menos água é um dos maiores desafios enfrentados pela humanidade.

BLANCO et al. (2011) avaliaram diferentes lâminas de irrigação para a produção de grãos verdes de feijão-caupi consorciado com o milho, em Teresina - PI. Estes autores observaram que o feijão-caupi respondeu linearmente à irrigação e que sua máxima produtividade foi obtida com lâmina de irrigação de 640 mm. SANTANA et al. (2008) afirmaram que a irrigação constitui a alternativa viável, dentre os tratos culturais, na melhoria da produtividade, e que sua finalidade básica é proporcionar água à cultura para atender à sua exigência hídrica.

NASCIMENTO et al. (2004), estudando o efeito da variação de níveis de água disponível no solo (40\%; 60\%; $80 \%$ e 100\%), sobre o crescimento e a produtividade de vagens e grãos verdes do feijão-caupi cultivar IPA 206, em Areia, Paraíba, verificaram que os diferentes níveis de água disponível no solo influenciaram significativamente no crescimento das plantas e na produtividade de grãos verdes do feijão-caupi.

O objetivo deste trabalho foi avaliar a produtividade de grãos verdes, os componentes de produção e a eficiência do uso de água do feijão-caupi, cultivares BRS Guariba e BRS Paraguaçu, sob diferentes regimes hídricos.

\section{MATERIAL E MÉTODOS}

O experimento foi conduzido em área experimental na Embrapa Meio-Norte, em Teresina, Piauí ( $5^{\circ} 05^{\prime} \mathrm{S}, 42^{\circ} 29^{\prime} \mathrm{W}$ e $72 \mathrm{~m}$ de altitude), no período de setembro a novembro de 2009 . O clima do município, de acordo com a classificação climática de Thornthwaite e Mather, é C1sA'a', caracterizado como subúmido seco, megatérmico, com excedente hídrico moderado no verão.

Os valores médios mensais de temperatura média do ar, umidade relativa média do ar, velocidade de vento e radiação solar durante a execução do experimento foram $29,3^{\circ} \mathrm{C}, 64,9 \%$, $0,94 \mathrm{~m} / \mathrm{s}^{-1}$ e $21,4 \mathrm{MJm}^{-2}$, respectivamente.

Avaliaram-se as cultivares de feijão-caupi BRS Guariba e BRS Paraguaçu. A semeadura foi realizada no dia 10 de setembro de 2009, sendo realizada com plantadeira manual, no espaçamento de 0,7 m x 0,2 m. Aos 15 dias após a semeadura, foi realizado o desbaste, deixando-se cinco plantas por metro. As características químicas e físico-hídricas do solo da área experimental estão descritas na Tabela 1. 
TABELA 1. Características químicas e físico-hídricas do solo da área experimental. Chemical and physic-hydric characteristics of experimental area soil.

\begin{tabular}{|c|c|c|}
\hline \multirow{2}{*}{ Característica } & \multicolumn{2}{|c|}{ Profundidade $(\mathrm{cm})$} \\
\hline & $0-20$ & $20-40$ \\
\hline$\overline{\mathrm{pH} \text { em } \mathrm{H}_{2} \mathrm{O}}$ & 5,78 & 5,37 \\
\hline Matéria orgânica (g kg-1) & 4,20 & 4,15 \\
\hline $\mathrm{P}\left(\mathrm{mg} \mathrm{dm}^{-3}\right)$ & 33,80 & 14,10 \\
\hline $\mathrm{K}+\left(\mathrm{cmol}_{\mathrm{C}} \mathrm{dm}^{-3}\right)$ & 0,17 & 0,13 \\
\hline $\mathrm{Ca}^{2+}\left(\mathrm{cmol}_{\mathrm{c}} \mathrm{dm}^{-3}\right)$ & 1,47 & 1,79 \\
\hline $\mathrm{Mg}^{2+}\left(\mathrm{cmol}_{\mathrm{c}} \mathrm{dm}^{-3}\right)$ & 0,76 & 0,58 \\
\hline $\mathrm{Na}^{+}\left(\mathrm{cmol}_{\mathrm{c}} \mathrm{dm}^{-3}\right)$ & 0,01 & 0,01 \\
\hline $\mathrm{H}^{+}+\mathrm{Al}^{3+}\left(\mathrm{cmol}_{\mathrm{C}} \mathrm{dm}^{-3}\right)$ & 2,15 & 3,38 \\
\hline Capacidade de troca catiônica $\left(\mathrm{cmol}_{\mathrm{C}} \mathrm{dm}^{-3}\right)$ & 4,56 & 5,89 \\
\hline Saturação por bases (\%) & 52,91 & 42,60 \\
\hline Densidade $\left(\mathrm{kg} \mathrm{dm}^{-3}\right)$ & 1,23 & 1,40 \\
\hline Capacidade de campo $\left(\mathrm{m}^{3} \mathrm{~m}^{-3}\right)$ & 0,22 & 0,22 \\
\hline Ponto de murcha permanente $\left(\mathrm{m}^{3} \mathrm{~m}^{-3}\right)$ & 0,09 & 0,11 \\
\hline Areia grossa $\left(\mathrm{g} \mathrm{kg}^{-1}\right)$ & 785 & 434 \\
\hline Areia fina $\left(\mathrm{g} \mathrm{kg}^{-1}\right)$ & 95 & 191 \\
\hline Silte $\left(\mathrm{g} \mathrm{kg}^{-1}\right)$ & 35 & 170 \\
\hline Argila (g kg ${ }^{-1}$ ) & 86 & 206 \\
\hline
\end{tabular}

Fonte: Laboratório de Solos da Embrapa Meio-Norte. Obs.: capacidade de campo à tensão matricial de $10 \mathrm{kPa}$.

Source: Embrapa Meio-Norte Soil Laboratory. Obs.: field capacity at matrix tension of $10 \mathrm{kPa}$.

A adubação consistiu na aplicação de $60 \mathrm{~kg}$ de $\mathrm{P}_{2} \mathrm{O}_{5}$ ha $^{-1}$ e de $40 \mathrm{~kg}$ de $\mathrm{K}_{2} \mathrm{O} \mathrm{ha}^{-1}$. Aos 20 dias após a semeadura, aplicaram-se $20 \mathrm{~kg}$ de $\mathrm{N} \mathrm{ha}^{-1}$ em cobertura. Realizaram-se tratos culturais de modo a manter a cultura livre de plantas daninhas, doenças e pragas. A irrigação foi efetuada por um sistema de aspersão convencional fixo, com aspersores de impacto no espaçamento de $12 \mathrm{~m} \mathrm{x}$ $12 \mathrm{~m}$.

Avaliaram-se cinco lâminas de irrigação, estabelecidas em função das seguintes frações da evapotranspiração de referência (ETo): 25\%, 50\%, 75\%, 100\% e 125\% . A ETo foi estimada pelo método de Penman-Monteith equação (1) (ALLEN et al., 1998) e os dados climatológicos foram obtidos em estação agrometeorológica automática a cerca de 500 m da área experimental.

$$
\text { ETo }=\frac{0,408 \Delta(R n-G)+\gamma \frac{900}{T+273} u_{2}\left(e_{s-} e_{\alpha}\right)}{\Delta+\gamma\left(1+0,34 u_{2}\right)}
$$

em que,

Eto - evapotranspiração de referência, $\mathrm{mm} \mathrm{dia}^{-1}$;

$\mathrm{Rn}$ - radiação líquida na superfície das culturas, $\mathrm{MJ} \mathrm{m}^{2} \mathrm{dia}^{-1}$;

$\mathrm{G}$ - fluxo de calor no solo, $\mathrm{MJ} \mathrm{m}^{2} \mathrm{dia}^{-1}$;

$\mathrm{T}$ - média diária da temperatura do ar a $2 \mathrm{~m}$ de altura, ${ }^{\circ} \mathrm{C}$;

$\mathrm{u}_{2}$ - velocidade do vento a $2 \mathrm{~m}$ de altura, $\mathrm{m} \mathrm{s}^{-1}$;

$\mathrm{e}_{\mathrm{s}}$ - pressão da saturação de vapor, $\mathrm{kPa}$;

$\mathrm{e}_{\mathrm{a}}$ - pressão de vapor atual, $\mathrm{kPa}$;

$\mathrm{e}_{\mathrm{s}}-\mathrm{e}_{\mathrm{a}}$ - déficit de saturação de vapor, $\mathrm{kPa}$;

$\Delta$ - inclinação da curva da pressão de vapor versus temperatura, $\mathrm{kPa}^{\circ} \mathrm{C}^{-1}$, e 
$\gamma$ - constante psicrométrica, $\mathrm{kPa}{ }^{\circ} \mathrm{C}^{-1}$.

A lâmina média de irrigação efetivamente aplicada em cada tratamento foi determinada imediatamente após cada irrigação, com base nas medições realizadas em 16 coletores espaçados em 3,0 x 3,0 m.

A irrigação foi uniforme para permitir o estabelecimento das plantas em todas as parcelas experimentais, durante os primeiros 30 dias após a semeadura, tendo sido realizada diariamente, com lâmina de água aplicada igual à ETo. Os tratamentos de irrigação foram iniciados a partir do trigésimo primeiro dia após a semeadura e estenderam-se até à colheita.

Utilizou-se o delineamento experimental de blocos ao acaso, com quatro repetições e tratamentos dispostos em parcelas subdivididas, em que as lâminas de irrigação foram distribuídas nas parcelas experimentais, e as cultivares, nas subparcelas.

O teor de água no solo foi monitorado diariamente, em camadas de 0,10 a 0,70 m de profundidade, por meio da sonda de capacitância elétrica, Diviner 2000. Instalaram-se três tubos de acesso para a medição do teor de água no solo, para cada tratamento.

A colheita foi realizada 56 e 60 dias após a semeadura, quando as vagens estavam bem intumescidas e começavam a sofrer leve mudança de tonalidade.

Ao final da colheita, as vagens foram debulhadas e foram avaliados a produtividade de grãos verdes e de vagem verde, o número de vagens verdes por planta, o comprimento médio de 10 vagens verdes, o número de grãos verdes por vagem e a massa de cem grãos verdes.

Calculou-se a eficiência do uso de água dividindo-se as produtividades de grãos verdes e de vagens verdes pelas lâminas de irrigação aplicadas (LACERDA et al., 2009). A fim de verificar a influência das lâminas de irrigação sobre a produtividade de grãos e vagens verdes do feijão-caupi, realizaram-se análises de variância e de regressão, utilizando-se do programa computacional estatístico SAS (SAS INSTITUTE, 2002).

\section{RESULTADOS E DISCUSSÃO}

A aplicação das frações de 25\%, 50\%, 75\%, 100\% e 125\% da ETo resultou nas seguintes lâminas totais de irrigação: 161 mm (L1), 196 mm (L2), 231 mm (L3), 275 mm (L4) e 322 mm (L5), nas cultivares de feijão-caupi BRS Guariba e BRS Paraguaçu, respectivamente. Ressalta-se que estas lâminas de irrigação são o resultado das medições realizadas em 16 coletores durante o período experimental e que não houve a ocorrência de precipitação pluviométrica, de modo que a resposta produtiva ocorreu apenas em função das lâminas diferenciadas de irrigação.

Como a diferenciação das lâminas de irrigação foi imposta somente a partir dos 30 dias após a semeadura (DAS), observou-se que não houve variações sensíveis no teor de água no solo, sob os cinco regimes de irrigação até esse período, os quais oscilaram entre $21 \%$ e 23\%, próximos, portanto, do limite superior de disponibilidade de água no solo (Tabela 1).

A partir do início da diferenciação dos tratamentos de irrigação (30 DAS), os teores de água no solo variaram de forma significativa, ou seja, o teor médio de água no solo manteve-se sempre elevado com a aplicação da maior lâmina de irrigação e decresceu com a aplicação das lâminas menores, tendo atingido os teores médios de umidade de 13\%, 15\%, 16\%, 19\% e 21\% (Figura 1), correspondendo a 31\%, 46\%, 54\%, 77\% e 92\% de água disponível no solo (AD), para as lâminas de irrigação equivalentes a 25\%, 50\%, 75\%, 100\% e 125\% da ETo, respectivamente. 


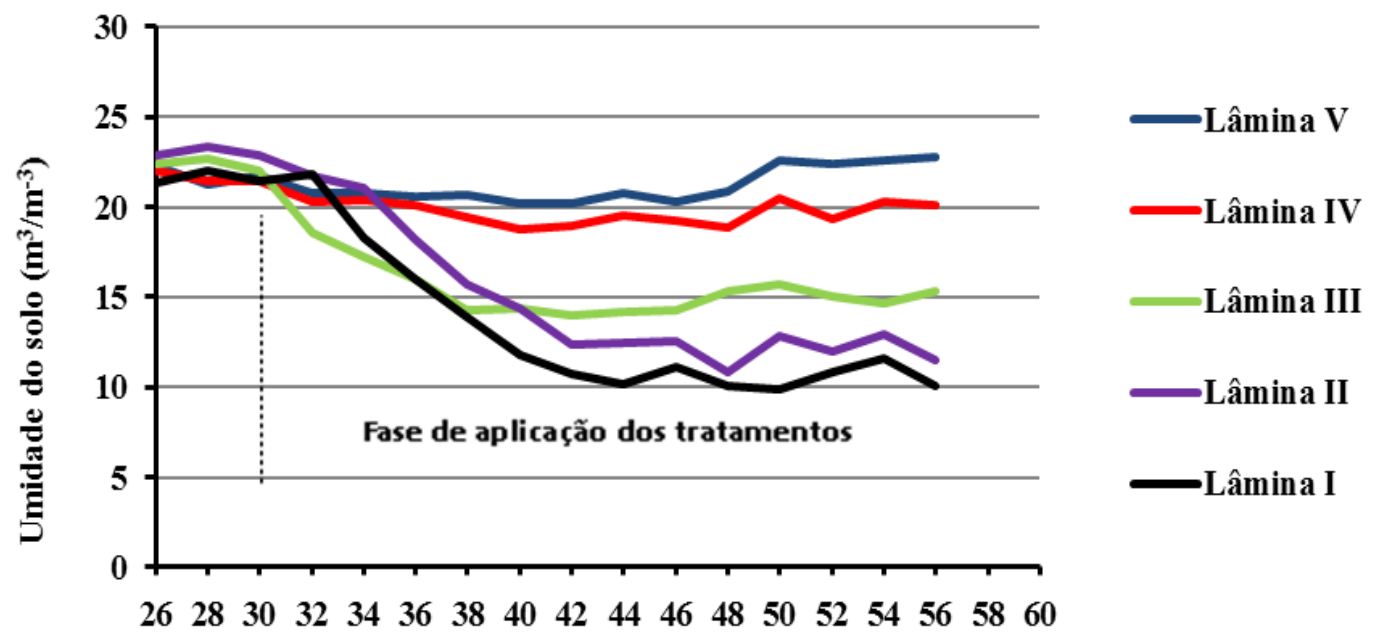

Dia após a semeadura

FIGURA 1. Variação do teor de água no solo para profundidade de $0,00 \mathrm{~m}$ a 0,20 m, ao longo do período do $26^{\circ}$ ao $56^{\circ}$ dias após a semeadura de feijão-caupi, em função das lâminas de irrigação aplicadas. Soil water content variation at depths of $0.00 \mathrm{~m}$ to $0.20 \mathrm{~m}$, from 26th day to 56th one, after cowpea-bean sowing according to applied irrigation blade.

A análise de variância (Tabelas 2 e 3) revelou efeito significativo das lâminas de irrigação para a produtividade de grãos verdes e produtividade de vagens verdes, para os seguintes componentes de produção: número de vagens verdes por planta, número de grãos verdes por vagem, comprimento médio de vagem verde e para a eficiência do uso de água das cultivares BRS Paraguaçu e BRS Guariba. Não houve diferença significativa para o componente de produção massa de cem grãos verdes.

TABELA 2. Resumo da análise de variância do número de vagens verdes por planta em raiz quadrada (RQNVP), comprimento médio das vagens verdes (CMV), número de grãos verdes por vagem em raiz quadrada (RQNGV) e produtividade de vagens verdes (PV) de duas cultivares de feijão-caupi, em função das lâminas de irrigação aplicadas. Variance analysis summary of green pods per plant under squared root (RQNVP), pod average length (CMV), green grain number per pod under squares root (RQNGV), and green grain yield (PV) for two cowpea-bean cultivars according to the applied irrigation blade.

\begin{tabular}{cccccc}
\hline \multirow{2}{*}{ F.V } & \multirow{2}{*}{ GL } & \multicolumn{4}{c}{ Quadrado médio } \\
\cline { 3 - 6 } & & RQNVP & CMV & RQNGV & PV \\
\hline BLOCO & 3 & $0,2300^{\text {n.s }}$ & $0,7342^{* *}$ & $0,0353^{\text {n.s }}$ & $1074177,83^{* *}$ \\
LÂM & 4 & $4,8082^{* *}$ & $4,7018^{* *}$ & $0,4858^{* *}$ & $12062382,86^{* *}$ \\
CULT & 1 & $0,0733^{\text {n.s }}$ & $3,3062^{*}$ & $0,7748^{* *}$ & $4207530,00^{\text {n.s }}$ \\
LÂM x CULT & 4 & $0,3918^{* *}$ & $1,1418^{\text {n.s }}$ & $0,2278^{* *}$ & $620209,28^{* *}$ \\
RESÍDUO & 27 & 17,6021 & 36,5397 & 3,4126 & 44763301,52 \\
\hline CV(\%) & & 7,95 & 3,80 & 3,97 & 11,96
\end{tabular}

FV - Fontes de variação; Lâm - lâminas de irrigação; Cult - Cultivar; ${ }^{\text {n.s }}$ - não Significativo, *, ** Significativo a nível de 5\% e $1 \%$ de probabilidade, respectivamente, pelo teste F. FV - Variation sources; Lâm - irrigation blades; Cult - cultivar; ${ }^{\text {ns }}$ - non-significant, \&, **, significant at 5 and $1 \%$, respectively, by $F$ test. 
TABELA 3. Resumo da análise de variância da produtividade de grãos verdes (PG), massa de cem grãos verdes (MCG), eficiência do uso de água para produtividade de grãos verdes (EUAPG) e para vagens verdes (EUAPV) de duas cultivares de feijão-caupi, em função das lâminas de irrigação aplicadas. Variance analysis summary of green grain yield (PG), on-hundred grain mass (MCG), water use efficiency for green grain yield (EUAPG) and green pods (EUAPV) for two cowpea-bean cultivars according to the applied irrigation blade.

\begin{tabular}{cccccc}
\hline \multirow{2}{*}{ F.V } & \multirow{2}{*}{ GL } & \multicolumn{5}{c}{ Quadrado médio } \\
\cline { 3 - 6 } & 3 & $279107,71^{* *}$ & MCG & EUAPG & EUAPV \\
\hline BLOCO & $3,9765^{\text {n.s }}$ & $5,6446^{* *}$ & $19,8684^{* *}$ \\
LÂM & 4 & $4853485,97^{* *}$ & $8,5369^{\text {n.s }}$ & $28,7238^{* *}$ & $40,8243^{* *}$ \\
CULT & 1 & $2454169,14^{* *}$ & $231,4902^{* *}$ & $38,2640^{* *}$ & $59,8517^{* *}$ \\
LÂM x CULT & 4 & $220885,98^{* *}$ & $7,2840^{\text {n.s }}$ & $2,2374^{* *}$ & $6,4626^{\text {n.s }}$ \\
RESÍDUO & 27 & 16987355,31 & 280,2897 & 128,4926 & 257,6583 \\
\hline CV(\%) & & 6,79 & 10,30 & 8,52 & 12,77 \\
\hline
\end{tabular}

FV - Fontes de variação; Lâm - lâminas de irrigação; Cult - cultivar; ${ }^{\text {n.s }}$ - não significativo, ** significativo a nível de $1 \%$ de probabilidade, pelo teste F. FV - Variation sources; Lâm - irrigation blades; Cult - cultivar; ${ }^{\text {ns }}$ - non-significant, \&, **, significant at 5 and $1 \%$, respectively, by $F$ test.

Esses resultados estão de acordo com os obtidos por NASCIMENTO et al. (2004), que estudando o crescimento e a produtividade de vagens e grãos verdes do feijão-caupi cultivar IPA 206, em Areia - PB, no qual verificaram que os diferentes níveis de água disponível no solo influenciaram significativamente no crescimento das plantas e na produtividade de grãos verdes do feijão-caupi.

Os valores da massa de 100 grãos foram 29,63/g (L1), 29,44/g (L2), 29,43/g (L3), 32,75/g (L4) e 32,32/g (L5), para a cultivar BRS Guariba, e 25,84/g (L1), 26,92/g (L2), 25,15/g (L3), 25,15/g (L4) e 27,49/g (L5), para a cultivar BRS Paraguaçu. Esses resultados confirmam a hipótese de que esse componente de produção não é influenciado por estresse hídrico.

As produtividades de grãos verdes das cultivares BRS Paraguaçu e BRS Guariba ajustaram-se a equações polinomiais quadráticas (Figura 2), sendo que as lâminas de irrigação que proporcionaram a máxima produtividade física de grãos verdes foram de $423 \mathrm{~mm}$ e $354 \mathrm{~mm}$., respectivamente, para as cultivares BRS Paraguaçu (2.498,04 $\mathrm{kg} \mathrm{ha}^{-1}$ ) e BRS Guariba (2.936,96 kg ha-1). Essas lâminas de irrigação estão abaixo das obtidas por Blanco et al. (2011), que avaliaram diferentes lâminas de irrigação para a produção de grão verde do feijão-caupi consorciado com o milho. A máxima produtividade foi obtida com lâmina de irrigação de $640 \mathrm{~mm}$ e foi superior à obtida por ROCHA et al. (2007) para a cultivar BRS Paraguaçu $\quad\left(1.977 \mathrm{~kg} \mathrm{ha}^{-}\right.$ ${ }^{1}$ ) e para a cultivar BRS Guariba $\left(1.750 \mathrm{~kg} \mathrm{ha}^{-1}\right)$, em condições de irrigação, avaliando o comportamento de 14 genótipos de feijão-caupi para produção de grãos verdes em Teresina - PI e por SILVA et al. (2013) analisando cultivares de feijão-caupi irrigado para produção de grãos verdes em Serra Talhada - PE. Esses autores observaram produtividade de grãos verdes de $1.687,01 \mathrm{~kg} \mathrm{ha}^{-1}$ para a cultivar BRS Guariba. 


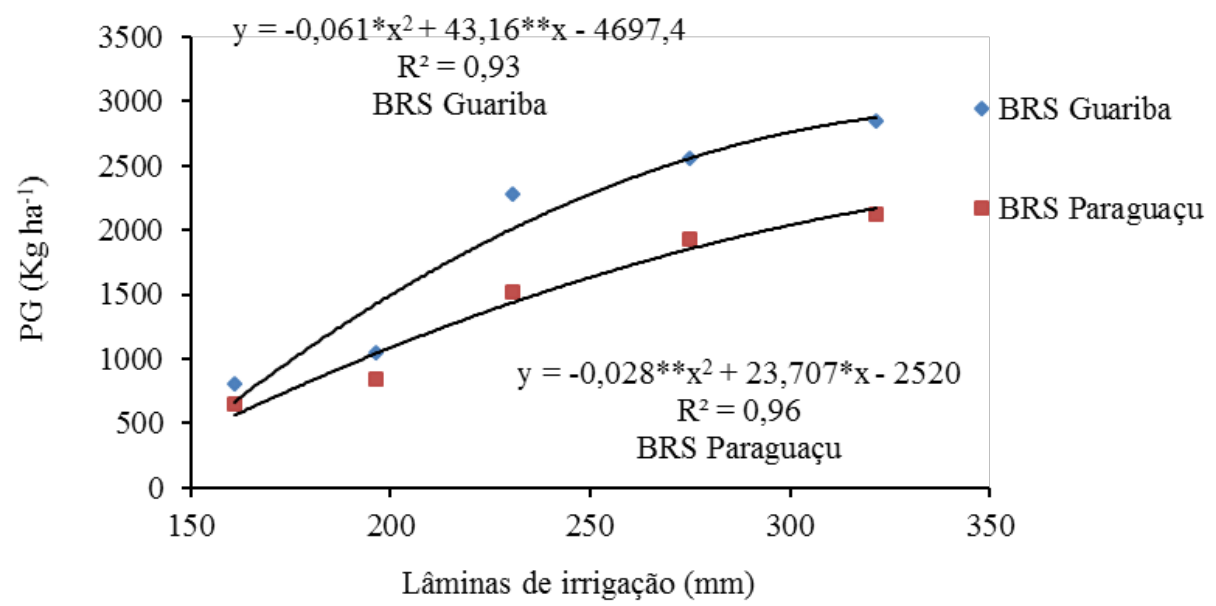

FIGURA 2. Produtividade de grãos verdes (PG) das cultivares BRS Guariba e BRS Paraguaçu, em função das lâminas de irrigação aplicadas, Teresina - PI. 2009. Green grain yield (PG) of BRS Guariba and BRS Paraguaçu cultivars according to applied irrigation blades, in Teresina, PI, Brazil, 2009.

A menor produtividade de grãos verdes foi de $571,0 \mathrm{~kg} \mathrm{ha}^{-1}$ e $670,6 \mathrm{~kg} \mathrm{ha}^{-1}$, para as cultivares BRS Paraguaçu e BRS Guariba, com aplicação das lâminas de irrigação de 161 mm (25\% ETo), respectivamente. Observa-se a redução significativa de 77,14 \% e 77,17 na produtividade de grãos verdes para as cultivares BRS Paraguaçu e BRS Guariba, respectivamente, com a redução das lâminas de irrigação que proporcionaram a máxima produtividade física, com $423 \mathrm{~mm}$ e $354 \mathrm{~mm}$ para BRS Paraguaçu e BRS Guariba, respectivamente, para a menor lâmina de irrigação, de 161 mm. Esses resultados estão de acordo com os obtidos por BASTOS et al. (2011), que observaram redução de $60 \%$ na produtividade de grãos feijão-caupi, identificando genótipos de feijão-caupi tolerantes à seca, em Teresina - PI.

Para o componente de produção número de vagens verdes por planta, o efeito médio das lâminas ajustou-se a uma função quadrática, para a cultivar BRS Paraguaçu e linear para a cultivar BRS Guariba (Figura 3). MOURA et al. (2009), ao avaliarem o efeito da lâmina de irrigação na produtividade do feijão-caupi no semiárido brasileiro, observaram resposta quadrática para a cultivar Pujante, com máxima NVP $(15,5)$ obtida com a lâmina de 442,7 mm.

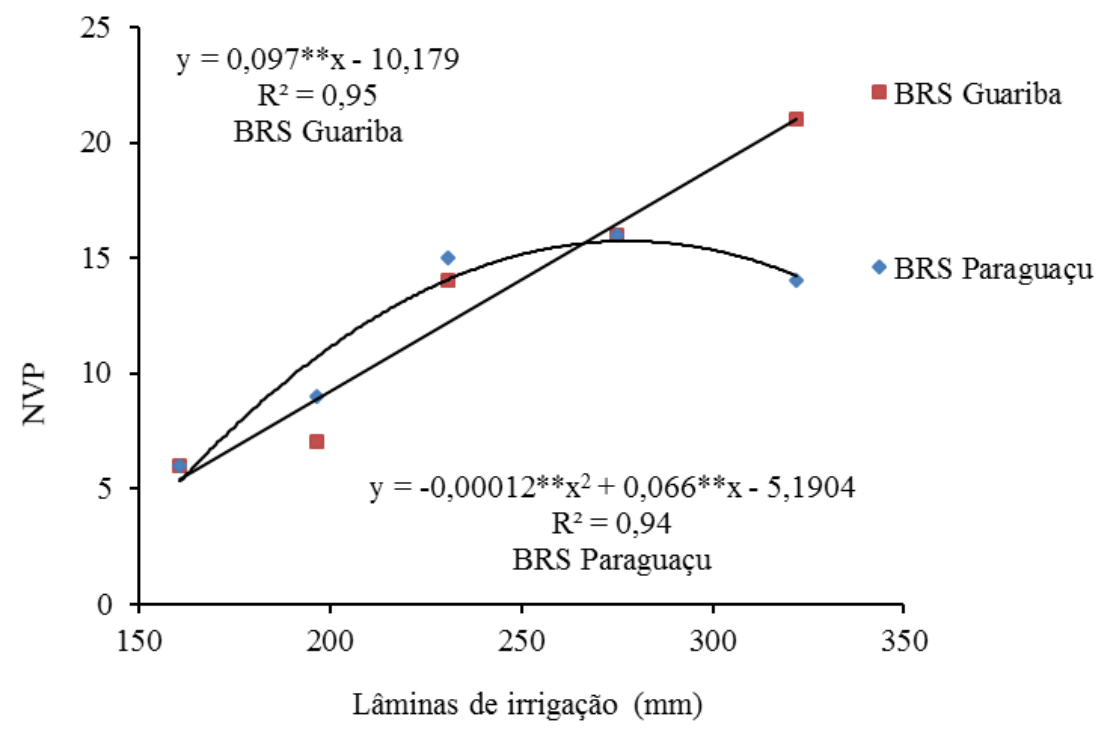

FIGURA 3. Número de vagens verdes por planta (NVP) das cultivares BRS Guariba e BRS Paraguaçu, em função das lâminas de irrigação aplicadas, Teresina - PI. 2009. Green pod per plant (NVP) of BRS Guariba and BRS Paraguaçu cultivars according to applied irrigation blades, in Teresina, PI, Brazil, 2009. 
O maior valor do número de vagens verdes por planta $(21,0)$, para a cultivar BRS Guariba, foi obtido com a aplicação das lâminas de irrigação de 322 mm (125\% ETo), e o máximo valor $(14,0)$, para cultivar BRS Paraguaçu, foi obtido com a aplicação das lâminas de irrigação de 274 mm (100\% ETo). Observa-se uma redução no número de vagens verdes por planta de $(12,0)$ da cultivar BRS Paraguaçu com a aplicação da maior lâmina de irrigação de $322 \mathrm{~mm}$ (125\% ETo). Esses resultados estão maiores que os obtidos por BRITO et al. (2012) avaliando a produtividade da água de chuva em culturas de subsistência no Semiárido pernambucano. Esses autores observaram número de vagens verdes por planta de $(8,1)$ para a cultivar de feijão-caupi BRS-Pujante. SANTOS et al. (2009), avaliando produção e componentes produtivos de variedades de feijão-caupi, na microrregião Cariri Oriental, Paraíba, observaram número de vagens verdes por planta de $(16,4)$ para a EPACE-10. Quanto à cultivar BRS Guariba, a maior lâmina de irrigação não reduziu o número de vagens verdes por planta, demonstrando o potencial produtivo dessa cultivar, comprovado pela maior produtividade.

O menor número de vagens verdes por planta $(5,0$ e 6,0) foi obtido com a aplicação da lâmina de irrigação de 161 mm (25\% ETo) para as cultivares BRS Guariba e BRS Paraguaçu, respectivamente. Observou-se a redução de $76 \%$ e $57 \%$ no número de vagens verdes por planta para as cultivares BRS Guariba e BRS Paraguaçu, respectivamente, com a redução das lâminas de irrigação de 322 mm (125\% ETo) para 161 mm (25\% ETo). BASTOS et al. (2011) observaram redução de $175 \%$ no número médio de vagens por planta, identificando genótipos de feijão-caupi tolerantes à seca, em Teresina - PI.

De acordo com NASCIMENTO et al. (2004), além de afetar a expansão foliar, a deficiência hídrica do solo pode causar o enrolamento e a abscisão, ou morte parcial das folhas, diminuição da brotação, polinização, translocação e enchimento de grãos, bem como o abortamento das vagens.

Quanto à produtividade de vagens verdes e número de grãos verdes por vagem, o efeito médio das lâminas ajustou-se a uma função linear para as duas cultivares (Figura 4).
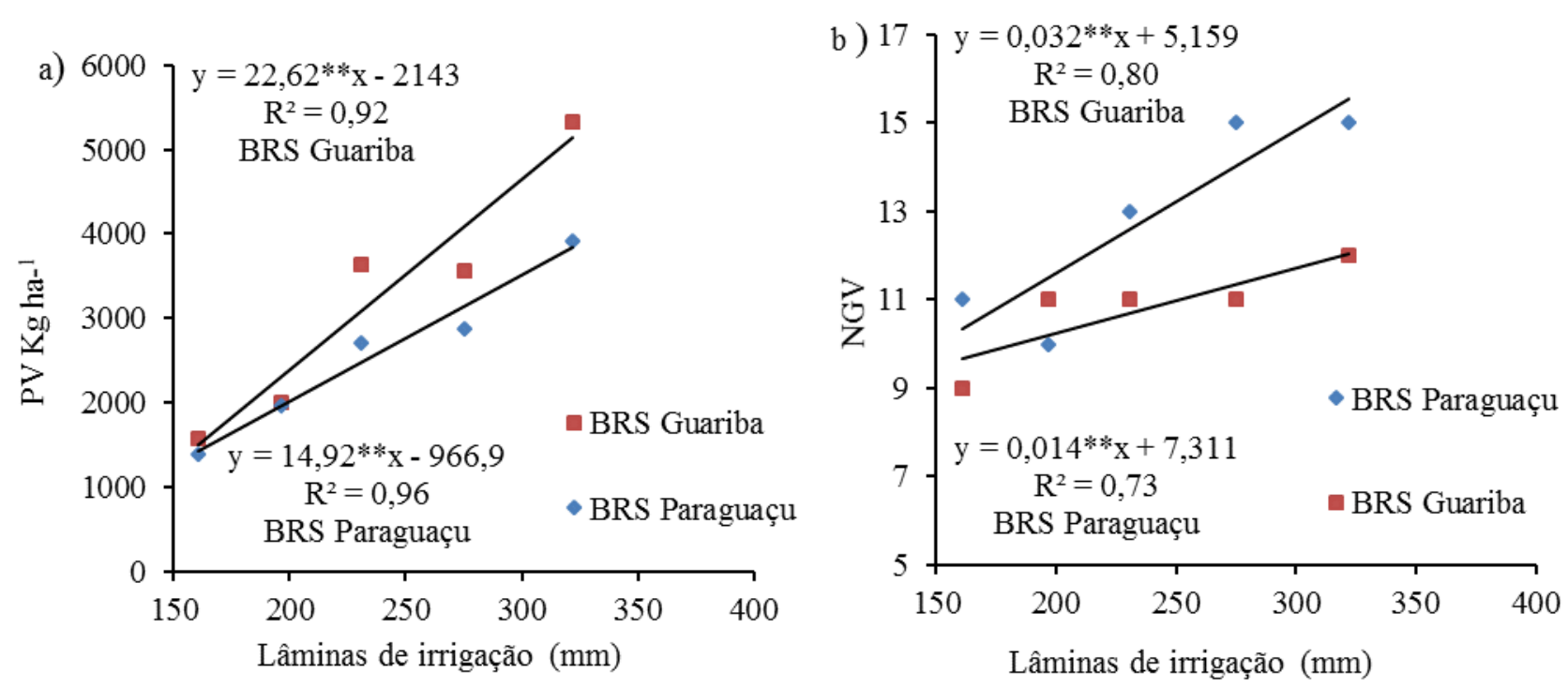

FIGURA 4. Produtividade de vagem verde (PV) (a), e o número de grãos por vagem por planta (NVP) (b), das cultivares BRS Guariba e BRS Paraguaçu, em função das lâminas de irrigação aplicadas, Teresina - PI. 2009. Green pod yield (PV) and grain number per pod per plant (NVP) of BRS Guariba and BRS Paraguaçu cultivars according to applied irrigation blades, in Teresina, PI, Brazil, 2009.

Para a produtividade de vagens verdes, os maiores valores foram de $3.840 \mathrm{~kg} \mathrm{ha}^{-1}$ e $5.145 \mathrm{~kg} \mathrm{ha}^{-1}$ obtidos com a aplicação da lâmina de irrigação de $322 \mathrm{~mm}$ (125\% ETo), respectivamente, para as cultivares BRS Paraguaçu e BRS Guariba. Esses resultados foram maiores 
que os obtidos por ROCHA et al. (2007) para a cultivar BRS Paraguaçu (3.364 kg ha ${ }^{-1}$ ) e para a cultivar BRS Guariba (3.494 $\mathrm{kg} \mathrm{ha}^{-1}$ ) em condições irrigadas, avaliando o comportamento de 14 genótipos de feijão-caupi para produção de grãos verdes em Teresina - PI.

As menores produtividade de vagens verdes foram de $1.437 \mathrm{~kg} \mathrm{ha}^{-1}$ e $1.502 \mathrm{~kg} \mathrm{ha}^{-1}$ obtidas com a aplicação da lâmina de irrigação de 161 mm (25\% ETo), respectivamente, para as cultivares BRS Paraguaçu e BRS Guariba.

Observa-se a redução de 62,6\% e 70,8\% na produtividade de vagens verdes para as cultivares BRS Paraguaçu e BRS Guariba, com a redução das lâminas de irrigação de 322 mm (125\% ETo) para 161 mm (25\% ETo), respectivamente. Essa redução ocorreu porque a deficiência hídrica reduz o potencial hídrico das plantas, diminuindo a condutância e a transpiração foliar. Como consequência, há aumento da temperatura foliar e redução na produção de fotoassimilados, causando redução na produtividade da cultura (TAIZ \& ZEIGER, 2009).

Para o número de grãos verdes por vagem, os maiores valores foram de 15,0 e 12,0, e os menores valores foram de 11,0 e 9,0 obtidas com a aplicação da lâmina de irrigação de $322 \mathrm{~mm}$ (125\% ETo) e $161 \mathrm{~mm}$ (25\% ETo), respectivamente, para as cultivares BRS Paraguaçu e BRS Guariba. Observa-se a redução significativa de 26,7\% e 25,0\% com a redução das lâminas de irrigação para as cultivares BRS Paraguaçu e BRS Guariba, respectivamente. SANTOS et al. (2009) constataram que a variedade de feijão-caupi EPACE-10 apresentou 13,69 grãos por vagem.

Quanto ao componente de produção comprimento médio das vagens verdes, o efeito médio das lâminas ajustou-se a uma função linear para as duas cultivares (Figura 5).

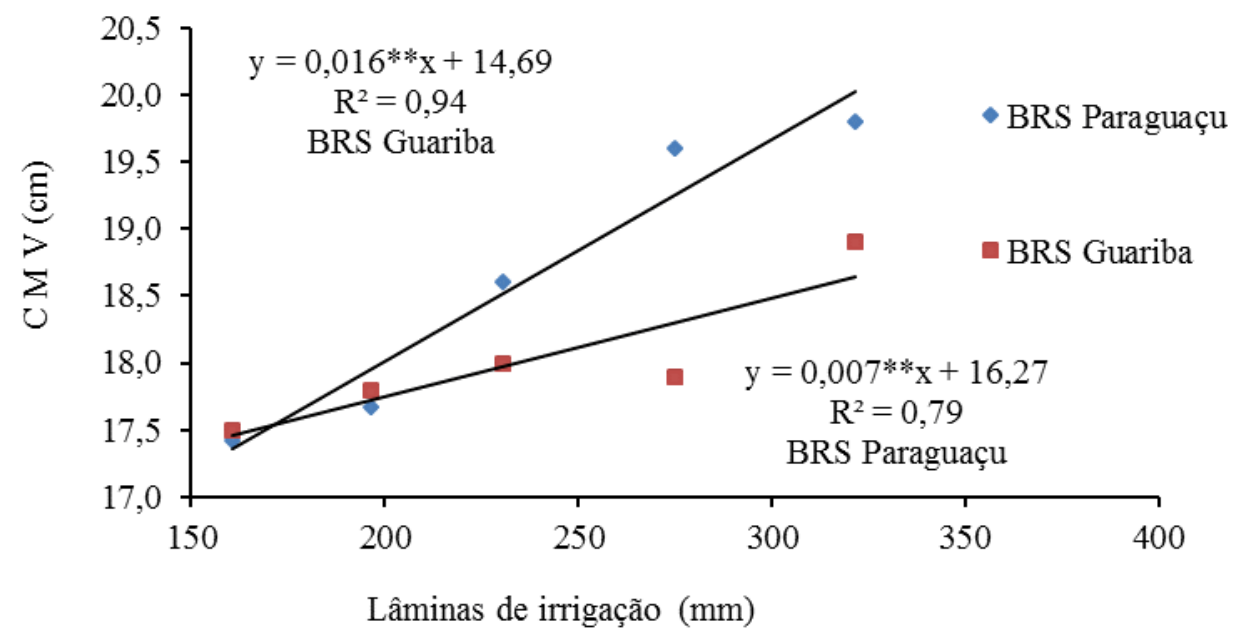

FIGURA 5. Comprimento médio de vagens verdes (CMV) das cultivares BRS Guariba e BRS Paraguaçu, em função das lâminas de irrigação aplicadas, Teresina - PI. 2009. Average green pod length (CMV) of BRS Guariba and BRS Paraguaçu cultivars according to applied irrigation blades, in Teresina, PI, Brazil, 2009.

Para o comprimento médio de vagens verdes (CMV), os maiores valores foram de 18,97 cm e 19,80 cm, e os menores foram de 17,42 cm e 17,57 cm, obtidos com a aplicação das lâminas de irrigação de 322 mm (125\% ETo) e 161 mm (25\% ETo) para as cultivares BRS Paraguaçu e BRS Guariba, respectivamente.

Observou-se a redução de 8,2 \% e 11,3\% com a redução das lâminas de irrigação para as cultivares BRS Paraguaçu e BRS Guariba, respectivamente. Esses resultados são semelhantes aos obtidos por NASCIMENTO et al. (2004), que observaram decréscimos crescentes do CMV com o aumento do déficit hídrico, com reduções de aproximadamente 8\%, 16\% e 24\%, referentes aos níveis de $80 \%, 60 \%$ e $40 \%$ de água disponível, respectivamente. 
De acordo com TAIZ \& ZEIGER (2009), essa menor redução do CMV em relação aos outros componentes de produção ocorreu porque, durante o déficit hídrico, os assimilados são dirigidos para os frutos e distanciados das raízes, razão pela qual o comprimento médio de vagens verdes tem menor sensibilidade ao estresse hídrico.

Para a eficiência do uso de água, o efeito médio das lâminas ajustou-se a uma função quadrática em relação à produtividade de grãos verdes e linear para a produtividade de vagens verdes das cultivares BRS Paraguaçu e BRS Guariba (Figura 6).

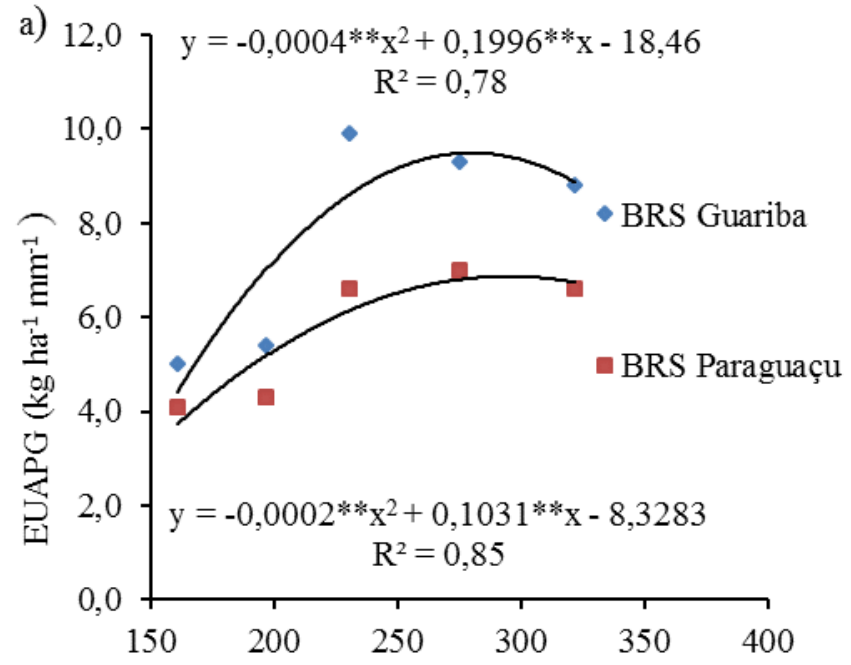

Lâminas de irrigação (mm)

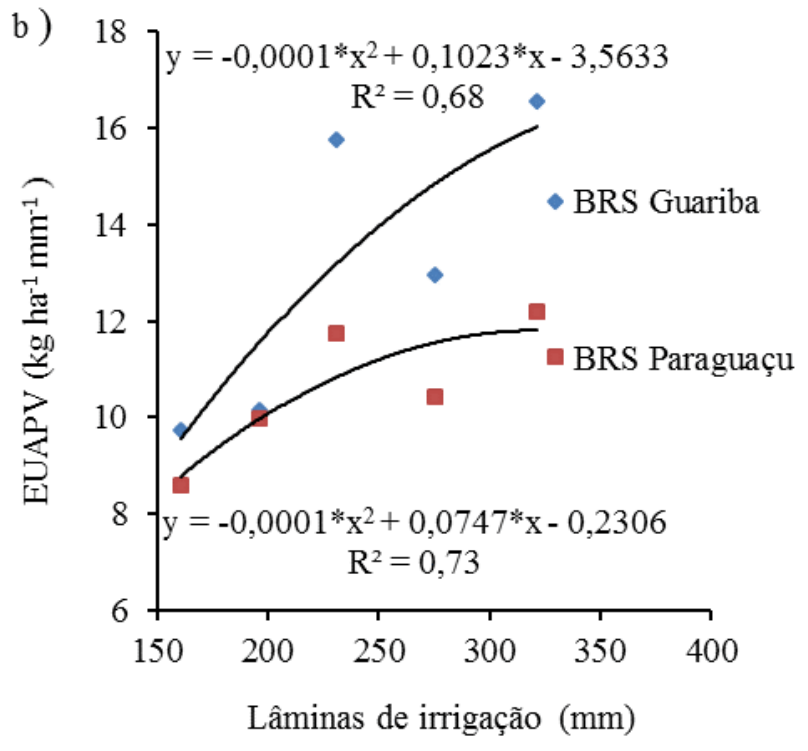

FIGURA 6. Eficiência do uso de água para a produtividade de grãos verdes (EUAPG) (a) e vagens verdes (EUAPV) (b) das cultivares BRS Guariba e BRS Paraguaçu, em função das lâminas de irrigação aplicadas, Teresina - PI. 2009. Water use efficiency for green grain yield (EUAPG) (a); and green pods (EUAPV) (b) of BRS Guariba and BRS Paraguaçu cultivars according to applied irrigation blades, in Teresina, PI, Brazil, 2009.

As máximas eficiências do uso de água para a produtividade de grãos verdes, 4,96 kg ha ${ }^{-1} \mathrm{~mm}^{-1}$ e 6,44 $\mathrm{kg} \mathrm{ha}^{-1} \mathrm{~mm}^{-1}$, foram obtidas com a aplicação das lâminas de irrigação de 257,5 mm e 249,5 mm, respectivamente, para as cultivares BRS Paraguaçu e BRS Guariba. Essas lâminas foram inferiores às que maximizaram a produção de grãos verdes para as cultivares BRS Paraguaçu (423 mm) e BRS Guariba (354 mm). De acordo com TAIZ \& ZEIGER (2009), quando o estresse hídrico é moderado, a eficiência do uso da água pode aumentar. Isso ocorre porque a taxa fotossintética da folha raramente é tão responsiva ao estresse hídrico moderado quanto à expansão foliar, pois a fotossíntese é muito menos sensível ao turgor do que a expansão foliar. Ou seja, mais $\mathrm{CO}_{2}$ pode ser absorvido por unidade de água transpirada. Isto acontece porque o fechamento estomático inibe a transpiração mais do que diminui as concentrações intercelulares de $\mathrm{CO}_{2}$.

BLANCO et al. (2011) avaliaram diferentes lâminas de irrigação para a produção de grãos verdes de feijão-caupi consorciado com o milho em Teresina, PI. Estes autores observaram eficiência do uso de água, com a média de 5,7 $\mathrm{kg} \mathrm{ha}^{-1} \mathrm{~mm}^{-1}$. LACERDA et al. (2009) observaram eficiência de utilização de água em plantas de feijão-de-corda irrigadas com água salina, de 3,0 a 5,8 $\mathrm{kg} \mathrm{MS} \mathrm{mm}^{-1}$. SOUZA et al. (2011) observaram que a eficiência do uso de água máxima é de $3,1 \mathrm{~kg} \mathrm{ha}^{-1} \mathrm{~mm}^{-1}$, aplicando-se uma lâmina de irrigação de 420,8 mm, avaliando a eficiência do uso da água das culturas do milho e feijão-caupi sob sistemas de plantio exclusivo e consorciado, no semiárido brasileiro, para produção de grãos secos.

Com relação à eficiência do uso de água para produtividade de vagem verde, os maiores valores (12,19 $\mathrm{kg} \mathrm{ha}^{-1} \mathrm{~mm}^{-1} \mathrm{e} 16,56 \mathrm{~kg} \mathrm{ha}^{-1} \mathrm{~mm}^{-1}$ ) foram obtidos com a aplicação da lâmina de 
irrigação de $322 \mathrm{~mm}$, correspondente ao tratamento de 125\% ETo, para as cultivares BRS Paraguaçu e BRS Guariba, respectivamente.

\section{CONCLUSÕES}

A produtividade de grãos verdes e vagens verdes, o número de vagens verdes por planta, o comprimento médio das vagens verdes e o número de grãos verdes por vagem diminuem com a redução das lâminas de irrigação.

A cultivar BRS Guaribas mostrou melhor desempenho produtivo quando comparada com a cultivar BRS Paraguaçu.

\section{REFERÊNCIAS}

ALLEN, R.G.; PEREIRA, L.S.; RAES, D.; SMITH, M. Crop evapotranspiration: guidelines for computing crop water requirements. Rome: FAO, 1998. 300p. (Irrigation and Drainage Paper, 56).

ANDRADE, F. N.; ROCHA, M. de M.; GOMES, R. L. F.; FREIRE FILHO, F. R.; RAMOS, S. R. R. Estimativas de parâmetros genéticos em genótipos de feijão-caupi avaliados para feijão fresco. Revista Ciência Agronômica, Fortaleza, v. 41, n. 2, p. 253-258, abr./jun. 2010.

BARROS, F. R.; ANUNCIAÇÃO FILHO, C. J. da; ROCHA, M. de M.; NUNES, J. A. R.; SILVA, K. J. D. e; FREIRE FILHO, F. R.; RIBEIRO, V. Q. Potencial genético de progênies de feijão-caupi segregantes ao tipo da inflorescência. Pesquisa Agropecuária Brasileira, Brasília, v. 46, n. 2, p. 182-189, fev. 2011.

BASTOS, E. A.; NASCIMENTO, S. P. do; SILVA, E. M. da; FREIRE FILHO, F. R.; GOMIDE, R. L. Identification of cowpea genotypes for drought tolerance. Revista Ciência Agronômica, Fortaleza, v. 42, n. 1, p. 100-107, jan./mar. 2011.

BENVINDO, R. N.; SILVA, J. A. L. da; FREIRE FILHO, F. R.; ALMEIDA, A. L. G. de; OLIVEIRA, J. T. S.; BEZERRA, A. A. de C. Avaliação de genótipos de feijão-caupi de porte semi-prostrado em cultivo de sequeiro e irrigado. Comunicata Scientiae, Bom Jesus, v. 1, n. 1 p. 2328, 2010.

BLANCO, F. F.; CARDOSO, M. J.; FREIRE FILHO, F. R.; VELOSO, M. E. da C.; NOGUEIRA, C. C. P.; DIAS, N. da S. Milho verde e feijão-caupi cultivados em consórcio sob diferentes lâminas de irrigação e doses de fósforo. Pesquisa Agropecuária Brasileira, Brasília, v. 46, n. 5, p. 524-530, maio, 2011.

BRITO, L. T. de L.; CAVALCANTI, N. de B.; SILVA, A. de S.; PEREIRA, L. A. Produtividade da água de chuva em culturas de subsistência no Semiárido Pernambucano. Engenharia Agrícola, Jaboticabal, v. 32, n.1, p. 102-109, 2012.

CHRISTOFIDIS, D. Água, irrigação e segurança alimentar. Revista Item, Brasília, n.77, p.16-21, 2008.

FREIRE FILHO, F. R.; CRAVO, M. da S.; RIBEIRO, V. Q.; ROCHA, M. de M.; CASTELO, E. de O.; BRANDÃO, E. dos S.; BELMINO, C. S.; MELO, M. Í. S. de. BRS Milênio e BRS Urubuquara: cultivares de feijão-caupi para a região Bragantina do Pará. Revista Ceres, Viçosa, MG, v. 56, n. 6, p. 749-752, nov./dez. 2009.

FREIRE FILHO, F. R.; ROCHA, M. de M.; RIBEIRO, V. Q.; RAMOS, S. R. R.; MACHADO, C. de F. Novo gene produzindo cotilédone verde em feijão-caupi. Revista Ciência Agronômica, Fortaleza, v. 38, n. 3, p.286-290, jul./set. 2007.

LACERDA, C.F.; NEVES, A.L.R.; GUIMARÃES, F.V.V.; SILVA, F.L.B.; PRISCO, J.T.; GHEYI, H.R. Eficiência de utilização de água e nutrientes em plantas de feijão-de-corda irrigadas com água salina em diferentes estádios de desenvolvimento. Engenharia Agrícola, Jaboticabal, v. 29, p.221230, 2009. 
MACHADO, C. de F.; TEIXEIRA, N. J. P.; FREIRE FILHO, F. R.; ROCHA, M de M; GOMES, R. L. F. Identificação de genótipos de feijão-caupi quanto à precocidade, arquitetura da planta e produtividade de grãos. Revista Ciência Agronômica, Fortaleza, v. 39, n. 1, p. 114-123, jan./mar. 2008.

MATOS FILHO, C. H. A.; GOMES, R. L. F.; ROCHA, M. de M.; FREIRE FILHO, F. R.; LOPES, A. C. de A. Potencial produtivo de progênies de feijão-caupi com arquitetura ereta de planta. Ciência Rural, Santa Maria, v. 39, n. 2, p. 348-354, mar./abr. 2009.

MOURA, M. S. B. de; SOUZA, L. S. B. de; SILVA, T. G. F. da; BRANDÃO. E. O.; SOARES, J. M. Efeito da lâmina de irrigação na produtividade do feijão-caupi no semi-árido brasileiro. In: CONGRESSO BRASILEIRO DE ENGENHARIA AGRICOLA, 38., 2009, Juazeiro, Petrolina. Planejamento da bacia hidrográfica e o desenvolvimento da agricultura... Juazeiro, Petrolina: UNIVASF, Embrapa Semiárido: CEFET: SBEA, 2009. 1 CD-ROM.

NASCIMENTO, J. T.; PEDROSA, M. B.; TAVARES SOBRINHO, J. Efeito da variação de níveis de água disponível no solo sobre o crescimento e produção de feijão-caupi, vagens e grãos verdes. Horticultura Brasileira, Brasília, v. 22, n. 2, p. 174-177, abr./jun. 2004.

ROCHA, M. de M.; SOARES, M. da C.; FREIRE FILHO, F. R.; RAMOS, S. R. R.; RIBEIRO, V. Q. Avaliação preliminar de genótipos de feijão-caupi para feijão-verde. Revista Científica Rural, Bagé, v. 12, n. 1, p. 153-156, 2007.

SANTANA, M.J.; CARVALHO, J.A.; ANDRADE, M.J.B.; BRAGA, J.C.; GERVÁCIO, G.G. Coeficiente de cultura e análise do rendimento do feijoeiro sob regime de irrigação. Irriga, Botucatu, v.13, n.1, p.92-112, 2008.

SANTOS J.F, GRANJEIRO J.I.T, BRITO C.H \& SANTOS M. Produção e componentes produtivos de variedades de feijão caupi na microregião cariri paraibano. Engenharia Ambiental, Espírito Santo do Pinhal, v. 06, n.1, p. 214-222, 2009.

SAS INSTITUTE. SAS/STAT user's guide. Version 8.1. Cary, 2002. v.1, 890p.

SILVA, E. F. da; BARROS JÚNIOR, A. P.; SILVEIRA, L. M. da. SANTANA, F. M. de S. SANTOS, M. G. dos. Avaliação de cultivares de feijão-caupi irrigado para produção de grãos verdes em Serra Talhada - PE. Revista Caatinga, Mossoró, v. 26, n. 1, p. 21-26, jan.-mar. 2013.

SOUZA, L. S. B. de; MOURA, M. S. B. de; S.; GILBERTO C.; SILVA, T. G. F. da. Eficiência do uso da água das culturas do milho e do feijão-caupi sob sistemas de plantio exclusivo e consorciado no semiárido brasileiro. Bragantia, Campinas, v.70, n.3, p. 715-721, 2011.

TAIZ, L.; ZEIGER, E. Fisiologia vegetal. 4. ed. Porto Alegre: Artmed, 2009. 820 p. 